\title{
IMPACT OF COVID-19 ON CRYPTOCURRENCIES: EVIDENCE ON INFORMATION TRANSMISSION THROUGH ECONOMIC AND FINANCIAL MARKET SENTIMENTS
}

\author{
Irfan Haider Shakri',Jaime Yong ${ }^{1}$, Erwei Xiang'
}

1. Edith Cowan University, Australia

* Corresponding Author: Irfan Haider Shakri, School of Business and Law, Edith Cowan University, Western Australia, $\triangle$ Email: irfanshakri@gmail.com

\begin{abstract}
This paper investigates the relationship between the COVID-19 crisis and the two leading cryptocurrencies, Bitcoin and Ethereum, from 31 December 2019 to 18 August 2020. We also use an economic news sentiment index and financial market sentiment index to explore the possible mechanisms through which COVID-19 impacts cryptocurrency. We employ a VAR Granger Causality framework and Wavelet Coherence Analysis and find the cryptocurrency market was impacted in the early phase of the sample period through economic news and financial market sentiments, but this effect diminished after June 2020 .
\end{abstract}

Keywords: Cryptocurrency, COVID-19, economic news sentiment, VIX, VAR Granger causality, Wavelet Coherence Analysis

\section{Introduction}

The cryptocurrency market is dominated by Bitcoin and Ethereum, each representing $65 \%$ and $14 \%$ of a USD941 billion market capitalization respectively. During the start of the COVID-19 outbreak worldwide, both currencies lost almost half of their value within days - Bitcoin observed a decrease from USD9,000 to USD5,000 in the first two weeks of March 2020. This study focuses on the price behaviour of the two leading cryptocurrencies and how this market reacted to a significant systemic risk event given the widespread coverage of the crisis in the media and heightened levels of financial market uncertainty.

Behavioural finance literature suggests the impact of news sentiment can influence investment behaviour (Da, Engelberg, \& Gao, 2015). Smales (2017) studied the importance of fear sentiment on the equity market returns and find significant effects. Further, market volatility measured with the VIX has greater influence on market returns during recessions. Li, Tian, Ouyang, and Wen (2020) concur, concluding that positive and negative sentiments lead to rises and falls in the returns of Chinese equity markets. Nitoi and Pochea (2020) examined the European markets using contagion and timevarying analysis and concluded that investors' perceptions are an important channel for the movement of markets in any direction, especially during times of crisis and economic uncertainty. Hence, there is ample literature to support the notion that financial markets are prone to move according to the sentiments of the investors, especially in the crisis situations.

Apart from equity markets, other studies have also been carried out to investigate the impact of the spread of COVID-19 crisis on the price behaviour of cryptocurrencies (Conlon \& McGee, 2020; Corbet, Larkin, \& Lucey, 2020; Mnif, Jarboui, \& Mouakhar, 2020). However, the studies carried out on the behaviour of cryptocurrencies at the onset of the pandemic could not address the transmission patterns of COVID-19 onto the cryptocurrency market. Gurdgiev, O'Loughlin, and Chlebowski (2019) studied the behaviour of cryptocurrency market and find herding behaviour during times of crisis 
driven by fear and uncertainty. Chen, Liu, and Zhao (2020) also presented that cryptocurrency market is affected during the COVID-19 pandemic due to the fear sentiment. Similar conclusions have been drawn by other studies as well (Shahzad, Bouri, Roubaud, Kristoufek, \& Lucey, 2019; Smales, 2019). This study considers the linkages and information flow from the rise in new cases and reported deaths each day on the cryptocurrency market through two channels: economic news sentiment and financial market sentiment.

In this paper, we use the economic news sentiment (ENS) index constructed by Shapiro, Sudhof, and Wilson (2020) to gauge public sentiment on economic news and the equity market volatility (VIX) index to measure financial market sentiment. In the initial months of the pandemic, new cases/deaths rose sharply worldwide along with the number of mortalities. The negative economic and financial news sentiment influenced the performance of financial markets including cryptocurrencies (Chen et al., 2020; Kang, Mclver, \& Hernandez, 2019). Amidst the crisis, several studies have been conducted to empirically test the impact of COVID-19 on several financial assets, their volatility and risks (Ali, Alam, \& Rizvi, 2020; Chen et al., 2020; Zaremba, Szyszka, Long, \& Zawadka, 2020). Our study aims to examine news sentiment (ENS) and equity market volatility (VIX) as paths or channels that impact of Bitcoin and Ethereum price behaviour during the spread of the pandemic using vector autoregression (VAR), Granger causality and wavelet coherence analysis (WCA).

\section{Data, Sample and Research Design}

Bitcoin and Ethereum daily prices were extracted from www.coindesk.com for a sample period from 31 December 2019 to 18 August 2020'. The daily data of the volatility index (VIX) was extracted from Thomson Reuters Eikon following the literature (e.g. (Akdağ, Kiliç, \& Yildirim, 2019; Albulescu, 2020)). The number of coronavirus cases and the number of coronavirus deaths reported daily was collected from the World Health Organization's website. We use the ENS data compiled by Shapiro et al. (2020) ${ }^{2}$ using positive and negative sentiments. The ENS index is compiled based on lexical analysis from economics-related news articles and is presented as sentiment scores drawn from a range of US published news with themes directly relating to "economics" and "United States". This ENS index has been utilized in a number of studies to test the impact of sentiment on risk and returns (Calomiris \& Mamaysky, 2019) and economic activity (Benhabib \& Spiegel, 2019). It has also been useful as a measure to capture sentiment at the onset of the global spread of COVID-19 (Aguilar, Ghirelli, Pacce, \& Urtasun, 2020).

\subsection{VAR Granger Causality}

Granger (1969) statistically explained that a cause $(x)$ occurs before its effect $(y)$ and knowledge of a cause $\left(x_{t-j}\right)$ improves the prediction of its effect. Following is the econometric explanation of the model used:

$$
C_{t}=\alpha+\sum_{i=1}^{m} \beta_{i} C_{t-i}+\sum_{j=1}^{n} \gamma_{j} P_{t-j}+\sum_{k=1}^{q} \theta_{k} V N_{t-k}+\varepsilon_{t}
$$

\footnotetext{
1 The sample period's end date of 18 August 2020 was chosen to isolate the ENS index from the effects of the US 2020 elections. The formalisation of the presidential candidates for both parties took place at this time.

2 See: https://www.frbsf.org/economic-research/indicators-data/daily-news-sentiment-index/.
} 


$$
\begin{aligned}
& P_{t}=\alpha+\sum_{j=1}^{n} \gamma_{j} P_{t-j}+\sum_{i=1}^{m} \beta_{i} C_{t-i}+\sum_{k=1}^{q} \theta_{k} V N_{t-k}+\varepsilon_{t} \\
& V N_{t}=\alpha+\sum_{k=1}^{q} \theta_{k} V N_{t-k}+\sum_{j=1}^{n} \gamma_{j} P_{t-j}+\sum_{i=1}^{m} \beta_{i} C_{t-i}+\varepsilon_{t}
\end{aligned}
$$

where, $C_{t}$ and $C_{t-i}$ denote daily changes to the natural logarithm of cryptocurrency prices namely, Bitcoin (BTC) and Ethereum (ETH) at time $t$ and its lagged values at time $t-i$ respectively. Daily changes to the natural logarithm of reported COVID-19 cases/deaths reported worldwide is represented as $P_{t}$ and $P_{t-j}$ for up to $j$ number of lags. The VIX and ENS are represented in the vector denoted $V N_{t}$ and $V N_{t-k}$ for up to $k$ lags. $\beta_{i}, \gamma_{j}$ and $\theta_{k}$ are the factor loadings for the cryptocurrency, new COVID-19 cases/deaths, VIX and ENS, respectively. $\alpha$ is a constant term and $\varepsilon_{t}$ is a mean stationary error term resembling white noise.

\subsection{Wavelet Coherence Analysis (WCA)}

Wavelet coherence analysis (WCA) has emerged in popularity to study the co-movement of time series variables, especially for the analysis of cryptocurrencies (Choi, 2020; Demir, Bilgin, Karabulut, \& Doker, 2020; Goodell \& Goutte, 2020). Our earlier analysis only allows us to establish if there is a transmission relationship between variables, but WCA allows us to look deeper into the timing of the effects. WCA plots the data into its frequency and time axes by rescaling the series (Crowley, 2007). This technique transforms a data series observed in discrete intervals into continuous waves to represent a continuous signal. The continuous wavelet transformation of a time series $x(t)$ is calculated as:

$$
W_{x(\tau, s)}=\int_{-\infty}^{\infty} x(t) \tilde{\psi}_{\tau, s}^{*}(t) d t
$$

Where, $W_{x}$ is the continuous wavelet transformation of a time series $x, T$ is the control parameter for wavelet in time, $s$ is the scaling parameter to determine the size of the wavelet, $\psi$ is the mother wavelet, and $\tilde{\psi}_{\tau, s}^{*}(t)$ is the complex conjugate function. Based on the cross wavelet transform, the coherence of the wavelets is given by (Torrence \& Webster, 1999):

$$
R_{x y}=\frac{\left|S\left(W_{x y}\right)\right|}{\left[S\left(\left|W_{x}\right|^{2}\right) S\left(\left|W_{y}\right|^{2}\right)\right]^{1 / 2}}
$$

where, $R_{x y}$ is the correlation coefficient (localized correlation coefficient in frequency-time space), $S$ is the smoothing operator in time and frequency, $W_{x}$ and $W_{y}$ are the wavelets for each time series and $W_{x y}$ is the cross wavelet.

\section{Empirical Results}

\subsection{VAR Granger Causality Results}

The pre-requisite before running the VAR model is stationarity of the variables. We used several methods for testing the stationarity of the variables, the results are not presented due to brevity. Table 1 provides the results of our VAR estimations. Based on the t-statistics, our findings suggest that changes to Bitcoin and Ethereum prices are not directly influenced by changes to daily case 
numbers/deaths (lqbal, Fareed, Wan, \& Shahzad, 2020). Instead, reports of new cases/deaths impact ENS over this period and hence the transmission of public sentiment regarding reports of growing numbers of new cases/deaths onto the cryptocurrency market is observed. There is also a unidirectional effect of market volatility on news sentiment, which suggests that while financial markets were reacting to increased volatility during this period, this may have further amplified changes to sentiment relating to the economic impact of the health pandemic. We also find significant impact of the VIX on cryptocurrency returns, as heighted volatility in financial markets may lead investors to seek 'safe haven' assets, in which cryptocurrencies have recently been regarded as.

Table 1: VAR Results for Bitcoin and Ethereum

\begin{tabular}{|c|c|c|c|c|c|c|c|c|}
\hline Panel A & $D(\ln B T C)$ & $D(E N S)$ & $D$ (InCASES) & $D(V I X)$ & $D(\operatorname{lnETH})$ & $D(E N S)$ & $D$ (InCASES) & $D(V I X)$ \\
\hline D (InBTC (-1)) & -0.02 & -0.014 & 0.001 & -6.635 & & & & \\
\hline D (InETH (-1)) & & & & & -0.067 & 0.004 & -0.076 & -3.676 \\
\hline$D($ ENS $(-1))$ & $0.387^{* *}$ & $0.289^{* * *}$ & -0.388 & 3.396 & $0.493^{* *}$ & $0.281^{* * *}$ & -0.333 & 3.773 \\
\hline$D(\operatorname{InCASES}(-1))$ & -0.015 & $0.012^{* * *}$ & $-0.218^{* * *}$ & 0.34 & -0.011 & $0.012^{* * *}$ & $-0.217^{* * *}$ & 0.321 \\
\hline$D(V I X(-1))$ & $-0.002^{* * *}$ & $-0.004^{* * *}$ & 0.001 & $-0.198^{* * *}$ & $-0.004^{* * *}$ & $-0.001^{* * *}$ & 0.000 & $-0.201^{* * *}$ \\
\hline C & 0.004 & $-0.002^{* * *}$ & $0.071^{* * *}$ & $0.055^{* * *}$ & $0.007^{* * *}$ & $-0.002^{* * *}$ & $0.072^{* * *}$ & 0.063 \\
\hline$R^{2}$ & 0.217 & 0.159 & 0.047 & 0.043 & 0.977 & 0.996 & 0.950 & 0.996 \\
\hline Adj. $R^{2}$ & 0.203 & 0.144 & 0.030 & 0.026 & 0.976 & 0.996 & 0.948 & 0.996 \\
\hline Sum Sq. Rsd. & 0.279 & 0.036 & 10.332 & 7407.21 & 0.438 & 9.211 & 7120.17 & 0.032 \\
\hline Panel B & $D(\ln B T C)$ & $D(E N S)$ & $D(\operatorname{InDEATHS})$ & $D(V I X)$ & $D(\ln E T H)$ & $D(E N S)$ & $D(\ln D E A T H S)$ & $D(V I X)$ \\
\hline$D(\operatorname{InBTC}(-1))$ & -0.031 & -0.021 & -0.146 & -9.057 & & & & \\
\hline D (InETH (-1)) & & & & & -0.071 & 0.004 & -0.067 & -3.675 \\
\hline D (ENS (-1)) & $0.506^{* * *}$ & $0.316^{* * *}$ & 0.098 & 12.317 & $0.536^{* *}$ & $0.290^{* * *}$ & 0.633 & 3.121 \\
\hline D (InDEATHS (-1)) & 0.023 & $0.017^{* *}$ & 0.155 & 2.518 & 0.016 & 0.002 & $0.609^{* * *}$ & 1.083 \\
\hline$D(\operatorname{VIX}(-1))$ & $-0.002^{* * *}$ & $-0.001^{* * *}$ & -0.000 & $-0.214^{* * *}$ & $-0.004^{* * *}$ & $-0.004^{* * *}$ & 0.000 & $-0.201^{* * *}$ \\
\hline c & 0.002 & -0.000 & $0.008^{* *}$ & 0.02 & $0.005^{* *}$ & $-0.001^{* *}$ & $0.025^{* * *}$ & 0.021 \\
\hline$R^{2}$ & 0.234 & 0.171 & 0.708 & 0.068 & 0.247 & 0.132 & 0.367 & 0.042 \\
\hline Adj. $R^{2}$ & 0.205 & 0.14 & 0.696 & 0.033 & 0.233 & 0.116 & 0.355 & 0.025 \\
\hline Sum Sq. Rsd. & 0.266 & 0.03 & 0.825 & 7202.3 & 0.464 & 0.032 & 1.785 & 7402.2 \\
\hline
\end{tabular}

Note: This table presents the results of the VAR estimation (using two different measures of COVID - 19 spread intensities in Panel A and Panel B) on first differences from Equation [1]. InBTC represents the log of Bitcoin prices, InETH represents the log of Ethereum prices, InCASES is the log of new COVID-19 cases reported each day, VIX is the volatility index and ENS is the Economic News Sentiment Index. ${ }^{*}, * *$ and ${ }^{* * *}$ represent significance at $10 \%, 5 \%$ and $1 \%$ respectively. 
While the initial VAR estimations first assume all variables are endogenous to the system of information transmission, we use the VAR Granger causality/ Block Exogeneity Wald test to further determine on a multivariate basis, the extent to which one variable Granger-causes another (see Table 2). Analysis presented in Table 1 and Table 2 using two separate measures of coronavirus cases and deaths report similar results. Our further analysis will focus on the number of cases due to two reasons. First, most countries followed a zero-transmission model in the early days of the pandemic where the focus was on daily infection numbers and this is captured in our sample period. Second, infection numbers may be more relevant than death numbers partly because infection numbers were more likely to cause panic at the time due to many unknowns about COVID at earlier stages and partly because deaths were largely amongst the elderly and people with other pre-existing conditions.

Table 2: VAR Granger causality/Block Exogeneity Wald Test Results

\begin{tabular}{|c|c|c|c|c|c|}
\hline \multicolumn{3}{|c|}{ Dependent variable: $D(\ln B T C)$} & \multicolumn{3}{|c|}{ Dependent variable: $D(I n E T H)$} \\
\hline Excluded & $X^{2}$ (InCASES) & $X^{2}$ (InDEATHS) & Excluded & $X^{2}$ (IICASES) & $X^{2}$ (IIDEATHS) \\
\hline $\mathrm{D}(\mathrm{ENS})$ & $4.973^{* *}$ & $6.53^{* *}$ & $D(E N S)$ & $4.68385^{* *}$ & 4.333 \\
\hline $\mathrm{D}(\operatorname{InCASES}) / \mathrm{D}(\operatorname{InDEATHS})$ & 2.028 & 0.868 & $\mathrm{D}(\operatorname{InCASES}) / \mathrm{D}(\operatorname{InDEATHS})$ & 0.61868 & 1.718 \\
\hline$D(V I X)$ & 54.32 & $51.72^{* * *}$ & $\mathrm{D}(\mathrm{VIX})$ & $65.26^{* * *}$ & $61.913^{* * *}$ \\
\hline All & $60.968^{* * *}$ & $59.38^{* * * *}$ & All & $70.3^{* * *}$ & $67.823^{* * *}$ \\
\hline \multicolumn{3}{|c|}{ Dependent variable: $D(E N S)$} & \multicolumn{3}{|c|}{ Dependent variable: $D(E N S)$} \\
\hline Excluded & $X^{2}$ (InCASES) & $X^{2}$ (InDEATHS) & Excluded & $X^{2}$ (InCASES) & $X^{2}$ (InDEATHS) \\
\hline $\mathrm{D}(\ln B T C)$ & $0.479^{* * *}$ & 0.812 & $\mathrm{D}(\mathrm{InETH})$ & 0.06015 & 0.36 \\
\hline $\mathrm{D}(\operatorname{InCASES}) / \mathrm{D}(\mathrm{InDEATHS})$ & $11.104^{* * *}$ & $7.928^{* *}$ & $\mathrm{D}(\operatorname{InCASES}) / \mathrm{D}(\operatorname{InDEATHS})$ & $10.76^{* * *}$ & $8.328^{* * *}$ \\
\hline$D(V I X)$ & $11.372^{* * *}$ & $11.46^{* * *}$ & $\mathrm{D}(\mathrm{VIX})$ & $12.06^{* * *}$ & $12.4^{* * *}$ \\
\hline All & $24.01^{* * *}$ & $21.79^{* * *}$ & All & $23.54^{* * *}$ & $21.29^{* * *}$ \\
\hline \multicolumn{3}{|c|}{ Dependent variable: $D$ (InCASES)/D(InDEATHS) } & \multicolumn{3}{|c|}{ Dependent variable: D(InCASES)/D(InDEATHS) } \\
\hline Excluded & $X^{2}$ (InCASES) & $X^{2}$ (IIDEATHS) & Excluded & $X^{2}$ (IICASES) & $X^{2}$ (InDEATHS) \\
\hline $\mathrm{D}(\ln B T C)$ & 0.000 & 1.503 & $\mathrm{D}(\mathrm{InETH})$ & 0.07646 & 2.305 \\
\hline $\mathrm{D}(\mathrm{ENS})$ & 0.135 & 2.333 & $\mathrm{D}(\mathrm{ENS})$ & 0.09717 & 2.378 \\
\hline$D(V I X)$ & 0.019 & 0.223 & $\mathrm{D}(\mathrm{VIX})$ & 0.02572 & 0.421 \\
\hline All & 0.154 & 3.35 & All & 0.23090 & 4.159 \\
\hline \multicolumn{3}{|c|}{ Dependent variable: $D(V I X)$} & \multicolumn{3}{|c|}{ Dependent variable: $D(V I X)$} \\
\hline Excluded & $X^{2}$ (InCASES) & $X^{2}$ (InDEATHS) & Excluded & $X^{2}$ (InCASES) & $X^{2}$ (InDEATHS) \\
\hline $\mathrm{D}(\ln B T C)$ & 0.46 & 2.074 & $\mathrm{D}(\mathrm{InETH})$ & 0.24312 & 0.475 \\
\hline $\mathrm{D}$ (ENS) & 0.014 & 2.038 & $D(E N S)$ & 0.01737 & 2.91 \\
\hline $\mathrm{D}$ (InCASES)/D(InDEATHS) & 0.037 & 0.371 & $\mathrm{D}(\operatorname{InCASES}) / \mathrm{D}(\operatorname{InDEATHS})$ & 0.03342 & 0.438 \\
\hline All & 0.486 & 5.637 & All & 0.26894 & 4.01 \\
\hline
\end{tabular}

Note: This table presents the results of VAR Granger Causality/Block Exogeneity Wald Test for Bitcoin and Ethereum against two separate measures for COVID - 19 intensities i.e., number of cases and number of deaths during the sample period. The null hypothesis of the test is that the lagged coefficients $=0$, i.e., that variable $\mathrm{x}$ does not Granger-cause variable $y$. The results are presented for individual and joint associations for all variables. ${ }^{*},{ }^{* *}$ and ${ }^{* * *}$ represent significance at $10 \%, 5 \%$ and $1 \%$ respectively.

The Forecast Error Variance Decomposition (FEVD) results in Table 3 show that up to $20 \%$ of the variance in the forecast error of Bitcoin returns can be explained by a unit shock in changes to the VIX index. However, ENS has a greater impact (approximately $22 \%$ ) on the forecast error of changes to Ethereum prices. From the VAR system of Bitcoin, we detect larger explanatory effects from market volatility and COVID-19 on news sentiment compared to the system with Ethereum, and suggest that findings related to Bitcoin are more informative, due to the dominance of this cryptocurrency in its 
market. While the FEVD for VIX indicates notable explanatory power of a unit shock in cryptocurrency returns and new COVID-19 cases, this is not supported in terms of market dynamics uncovered from our earlier analysis. We do not elaborate on the forecast error of new COVID-19 cases, as it is not meaningful.

Table 3: VAR Variance Decomposition Model

\begin{tabular}{|c|c|c|c|c|c|c|c|c|c|c|c|}
\hline \multicolumn{6}{|c|}{ Variance Decomposition of D(InBTC) } & \multicolumn{6}{|c|}{ Variance Decomposition of $D(\operatorname{InETH})$} \\
\hline Period & S.E. & $\mathrm{D}(\ln \mathrm{BTC})$ & $D(\operatorname{InCASES})$ & $D(V I X)$ & $\mathrm{D}$ (ENS) & Period & S.E. & D(InETH) & D(InCASES) & $\mathrm{D}(\mathrm{VIX})$ & D(ENS) \\
\hline 1 & 0.0353 & 100.00 & 0.0000 & 0.0000 & 0.0000 & 1 & 0.0459 & 100.00 & 0.0000 & 0.0000 & 0.0000 \\
\hline 2 & 0.0398 & 78.943 & 0.5802 & 18.946 & 1.5291 & 2 & 0.0525 & 76.581 & 1.7830 & 0.1160 & 21.519 \\
\hline 3 & 0.0400 & 78.416 & 0.7267 & 19.237 & 1.6198 & 3 & 0.0528 & 75.783 & 1.7989 & 0.2081 & 22.209 \\
\hline 4 & 0.0400 & 78.352 & 0.7265 & 19.290 & 1.6296 & 4 & 0.0528 & 75.683 & 1.8070 & 0.2080 & 22.301 \\
\hline 5 & 0.0400 & 78.350 & 0.7272 & 19.292 & 1.6301 & 5 & 0.0528 & 75.679 & 1.8071 & 0.2084 & 22.304 \\
\hline \multicolumn{6}{|c|}{ Variance Decomposition of D(InCASES) } & \multicolumn{6}{|c|}{ Variance Decomposition of D(InCASES) } \\
\hline Period & S.E. & $\mathrm{D}(\ln B T C)$ & D(InCASES) & $D(V I X)$ & D(ENS) & Period & S.E. & $D(\operatorname{InETH})$ & D(InCASES) & $D(V I X)$ & D(ENS) \\
\hline 1 & 0.2152 & 0.0008 & 0.0808 & 0.1074 & 99.810 & 1 & 0.0127 & 0.5065 & 99.493 & 0.0000 & 0.0000 \\
\hline 2 & 0.2203 & 0.1241 & 3.9907 & 4.6188 & 91.266 & 2 & 0.0138 & 0.6236 & 90.861 & 4.1102 & 4.4047 \\
\hline 3 & 0.2205 & 0.1236 & 3.9905 & 4.5982 & 91.287 & 3 & 0.0138 & 0.6336 & 90.840 & 4.0975 & 4.4285 \\
\hline 4 & 0.2205 & 0.1243 & 3.9999 & 4.6160 & 91.259 & 4 & 0.0138 & 0.6342 & 90.809 & 4.1102 & 4.4455 \\
\hline 5 & 0.2205 & 0.1243 & 4.0001 & 4.6159 & 91.259 & 5 & 0.0138 & 0.6342 & 90.809 & 4.1102 & 4.4458 \\
\hline \multicolumn{6}{|c|}{ Variance Decomposition of $D(V I X)$} & \multicolumn{6}{|c|}{ Variance Decomposition of D(VIX) } \\
\hline Period & S.E. & $\mathrm{D}(\ln B T C)$ & $\mathrm{D}$ (InCASES) & $D(V I X)$ & D(ENS) & Period & S.E. & $D($ InETH) & $D$ (InCASES) & $D(V I X)$ & D(ENS) \\
\hline 1 & 5.7633 & 0.1175 & 99.8824 & 0.0000 & 0.0000 & 1 & 0.2152 & 0.1242 & 0.0935 & 99.782 & 0.0000 \\
\hline 2 & 5.8828 & 0.1169 & 99.8233 & 0.0093 & 0.0502 & 2 & 0.2203 & 0.1818 & 0.1060 & 99.701 & 0.0105 \\
\hline 3 & 5.8926 & 0.1171 & 99.822 & 0.0094 & 0.0504 & 3 & 0.2205 & 0.1840 & 0.1082 & 99.689 & 0.0179 \\
\hline 4 & 5.8932 & 0.1171 & 99.822 & 0.0094 & 0.0505 & 4 & 0.2205 & 0.1843 & 0.1083 & 99.688 & 0.0186 \\
\hline 5 & 5.8933 & 0.1171 & 99.822 & 0.0094 & 0.0505 & 5 & 0.2205 & 0.1843 & 0.1083 & 99.688 & 0.0188 \\
\hline \multicolumn{6}{|c|}{ Variance Decomposition of D(ENS) } & \multicolumn{6}{|c|}{ Variance Decomposition of D(ENS) } \\
\hline Period & S.E. & $D(\ln B T C)$ & $D($ InCASES) & $D(V I X)$ & D(ENS) & Period & S.E. & $D($ InETH $)$ & $D($ InCASES) & $D(V I X)$ & D(ENS) \\
\hline 1 & 0.0127 & 0.0510 & 0.0569 & 99.891 & 0.0000 & 1 & 5.7661 & 0.0642 & 0.0761 & 0.0560 & 99.803 \\
\hline 2 & 0.0138 & 0.2415 & 0.0832 & 99.669 & 0.0053 & 2 & 5.8842 & 0.1132 & 0.0906 & 0.0807 & 99.715 \\
\hline 3 & 0.0138 & 0.2501 & 0.0830 & 99.658 & 0.0080 & 3 & 5.8927 & 0.1165 & 0.0927 & 0.0813 & 99.709 \\
\hline 4 & 0.0138 & 0.2508 & 0.0831 & 99.657 & 0.0080 & 4 & 5.8933 & 0.1168 & 0.0928 & 0.0813 & 99.709 \\
\hline 5 & 0.0138 & 0.2508 & 0.0831 & 99.657 & 0.0080 & 5 & 5.8933 & 0.1168 & 0.0928 & 0.0813 & 99.709 \\
\hline
\end{tabular}

Note: This table presents the VAR Variance Decomposition Model for all the variables used in this study both with the Bitcoin prices and Ethereum prices. LnBTC indicates log of Bitcoin prices; InETH indicated log of Ethereum prices; InCASE represents the number of cases reported during COVID-19; VIX represents the volatility index and ENS is the economic news sentiment.

The impulse response functions of Figure 1 shows that an upward shock up to one standard deviation (innovations) in cryptocurrency returns leads to an immediate increase in next day returns, and the effect starts to diminish then dissipate after 2 days. The impact of a shock to changes in ENS causes an initial increase to cryptocurrencies for 2 days, after which it starts to decrease and dissipate by the third day. In contrast, an initial upward shock in the VIX results in a negative response for cryptocurrencies for up to 2 days but reverses and the effects do not persist for more than 4 days. Comparatively there is very little response in cryptocurrencies from shocks to new daily coronavirus cases. Innovations to one-period lagged changes to ENS causes an initial increase to current sentiment, and the effects start to diminish but can remain persistent for up to 4 days. We also find a 
positive one standard deviation shock to new coronavirus cases has an increasing impact on news sentiment for up to 2 days afterward, then diminishes and dissipates after the $3^{\text {rd }}$ day. However, there is an inverse response to changes in news sentiment resulting from a positive shock to VIX but after 2 days this reverts and is no longer persistent after 3 days. The IRFs also show that there is little to no impact of innovations from the cryptocurrency markets, news sentiment or market volatility on new cases, as expected. VIX is also largely only impacted by innovations to its own past values.

\section{Figure 1: Impulse Response of Bitcoin and Ethereum in response to one standard deviation shocks to the Economic News Sentiment, Volatility Index (VIX) and new daily COVID-19 cases reported during the period.}
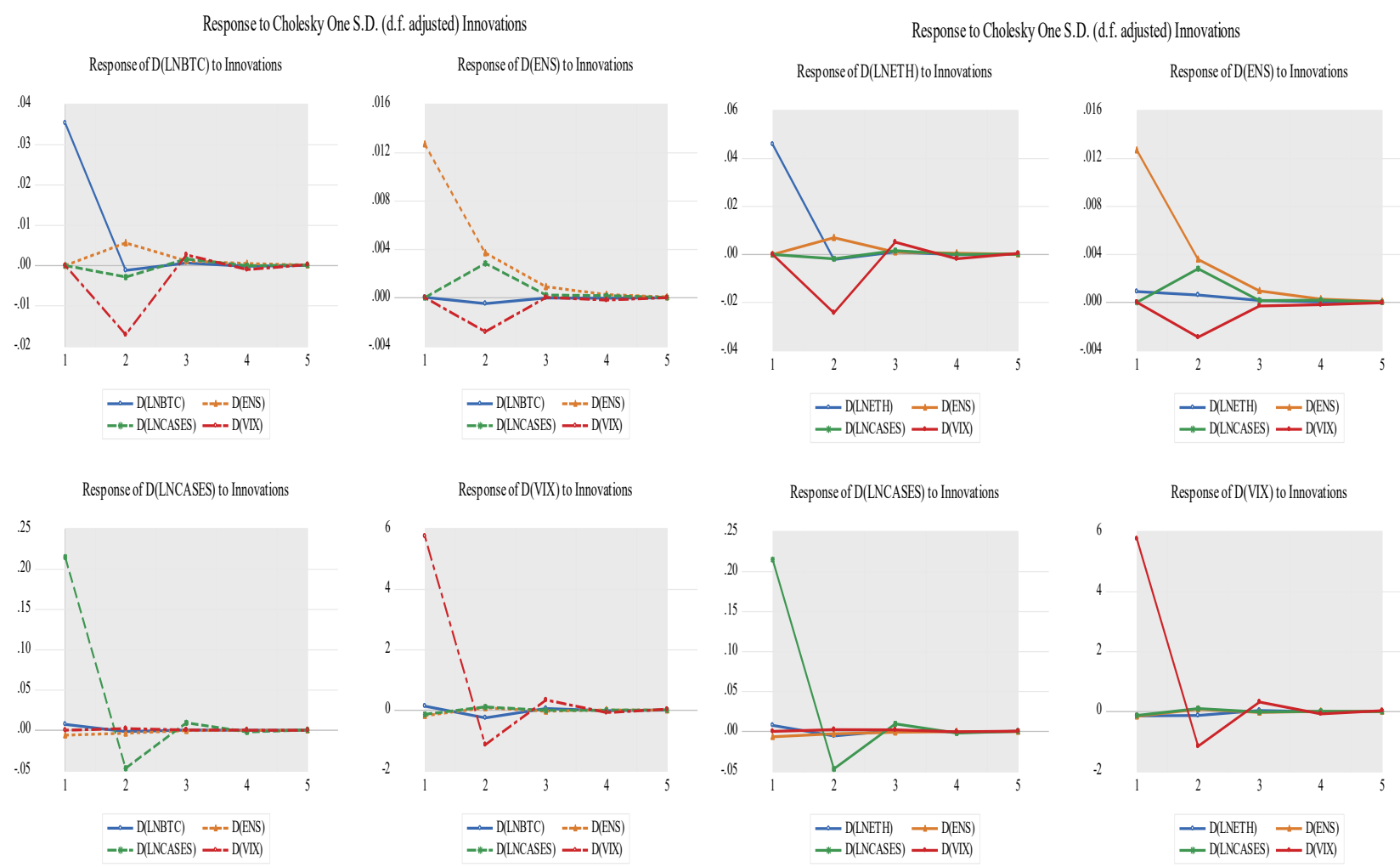

\subsection{Wavelet Coherence Analysis Results}

Before the application of WCA for Bitcoin and Ethereum prices, we first attempt to understand the information transmission flows of the other three variables i.e. daily cases of COVID-19, VIX and ENS. Extending from our previous analysis, we aim to determine how the responses of these variables to each other evolved over the eight months of our sample period in terms of their correlations and their lead/lag relations. We divided our sample period into three phases: Initial phase - the start of COVID-19, where first reports of cases found in China and sporadic cases found in some other countries, when there were no travel restrictions and no strict lockdowns imposed globally (start to 28 th February 2020); Middle phase - reports of cases started to rise in other countries indicating the accelerating spread of the pandemic globally, when travel restrictions and strict lockdowns were imposed globally and new cases were on the rise (March 01, 2020 to June 30, 2020), and Later phase - when most of the countries including Europe re-opened their borders but there was economic slowdown (July 1, 2020 to August 18, 2020).

From Figure $2(1 \mathrm{~A})$ the wavelet coherence does not show any correlation between ENS and VIX in the initial phase of the sample period, as during this time the spread of the pandemic was limited to 
a few countries and there were no widespread reports globally. However, as we move forward on the timeline, the arrows within the cone of influence point leftward meaning that ENS and VIX were inversely related to each other during the middle phase with a high magnitude of correlation (shaded yellow). On the top side of the graph, some evidence of very high magnitude has been observed pointing right indicating that changes to the VIX index leads ENS during the middle phase. However, within the cone of influence, there is no evidence of high correlation between ENS and VIX during the later phase of the sample period. There is evidence of correlation between COVID-19 cases and ENS in Figure 3 (1B) with strong correlations in the initial and middle phases. However, no strong correlation has been observed between COVID-19 cases and VIX in Figure 3 (1C). These results are consistent with our previous analysis of VAR Granger Causality and Block Exogenous Wald test.

\section{Figure 2: Wavelet Coherence Graphical Matrix}

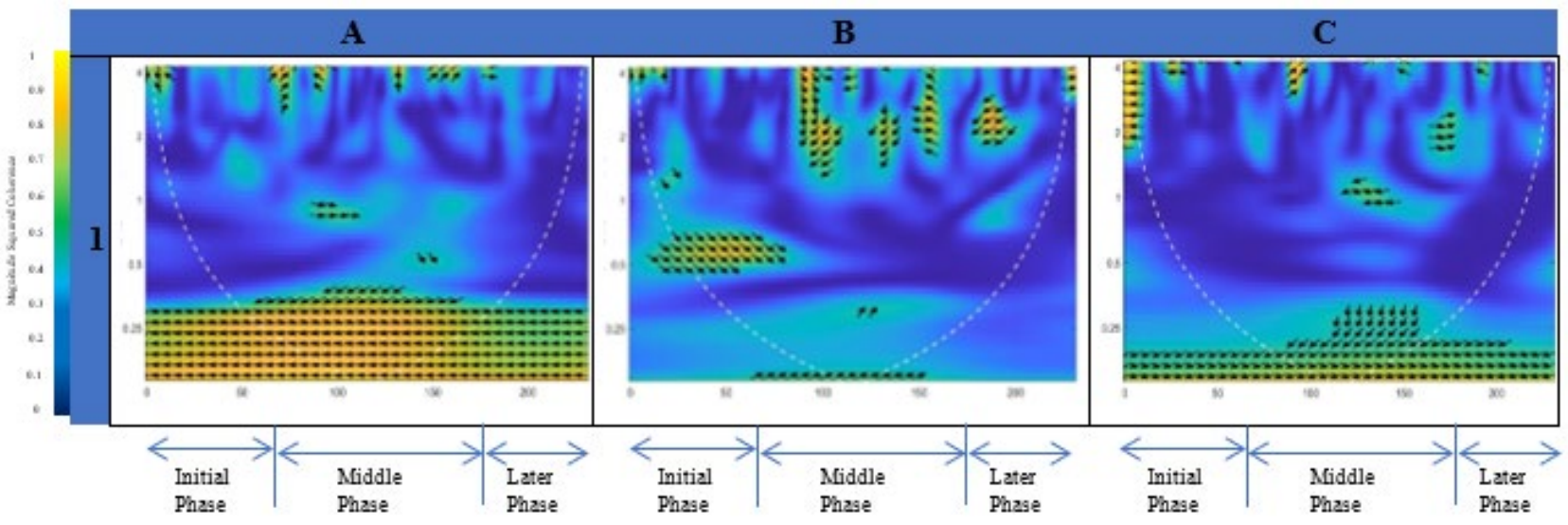

Note: In the above wavelet coherence graphical matrix, 1A represents the coherence of economic new sentiment (ENS) and equity market volatility index (VIX), 1B represents coherence between COVID-19 cases and ENS, and IC represents the coherence between COVID-19 cases and VIX. The horizontal axis represents 'time (in days) ' whereas the vertical axis represents the 'frequency (cycles/sample)'. On the left side of the matrix, the magnitude coherence scale is presented between 0 (blue) and 1 (yellow). The whole sample period is divided into three phases i.e. initial phases from start of the period until $28^{\text {th }}$ February 2020, the middle phase - March 01 , 2020 to June 30, 2020, and the later phase ranges from July 1, 2020 to August 18, 2020. Arrows indicate phase differences. Arrows pointing to the right show a positive correlation and vice versa. If the arrows point downwards, this means the first series leads the second one; if they point upwards, this means the second series leads the first one.

WCAs of COVID-19 cases, ENS and VIX with Bitcoin and Ethereum prices are presented in Figure 3 observe no signs of correlation between Bitcoin prices and COVID-19 cases in the initial phases (see Figure 3 ( $1 \mathrm{~A}$ and $1 \mathrm{~B})$ ) as compared to Ethereum that shows low correlation with COVID-19 cases in the initial phase. This may be due to the fact that Bitcoin is the leading cryptocurrency with higher capital flows and prices as compared to Ethereum. The upward arrows in the middle phase indicates COVID-19 cases have led fluctuations in Bitcoin prices but this was not dominant. In the later phase both Figures 4 (1A) and (1B) show strong correlation between prices of these currencies and COVID19 cases. We can conclude that the spread of the pandemic has not predominantly or directly affected Bitcoin and Ethereum prices, as suggested by other similar studies (Choi, 2020; Goodell \& Goutte, 2020).

Figure 3 (2A and $2 \mathrm{~B}$ ) shows no consistent signs of correlation throughout the initial, middle, and later phases have been observed for Bitcoin (see Figure $32 \mathrm{~A}$ ) and Ethereum (see Figure 3 2B) prices with ENS, rather, except for the Ethereum that has shown moderate correlation in the middle phase with ENS. A very strong and negative correlation between Bitcoin prices and VIX (Figure 3, 3A), and Ethereum and VIX (Figure 3, 3B) has been observed in the initial and middle phases. The equity market volatility led the cryptocurrency prices negatively during the initial and middle phases. However, the later phase has not observed any sign of strong correlation with VIX. Through all the observations, we 
conclude that the prices of the Bitcoin and Ethereum are mainly influenced by the information flow of COVID-19 cases to ENS and VIX during the initial and middle phases and then the rehabilitation process occurs in the later phases where no strong correlation was observed.

\section{Figure 3: Wavelet Coherence Graphical Matrix}
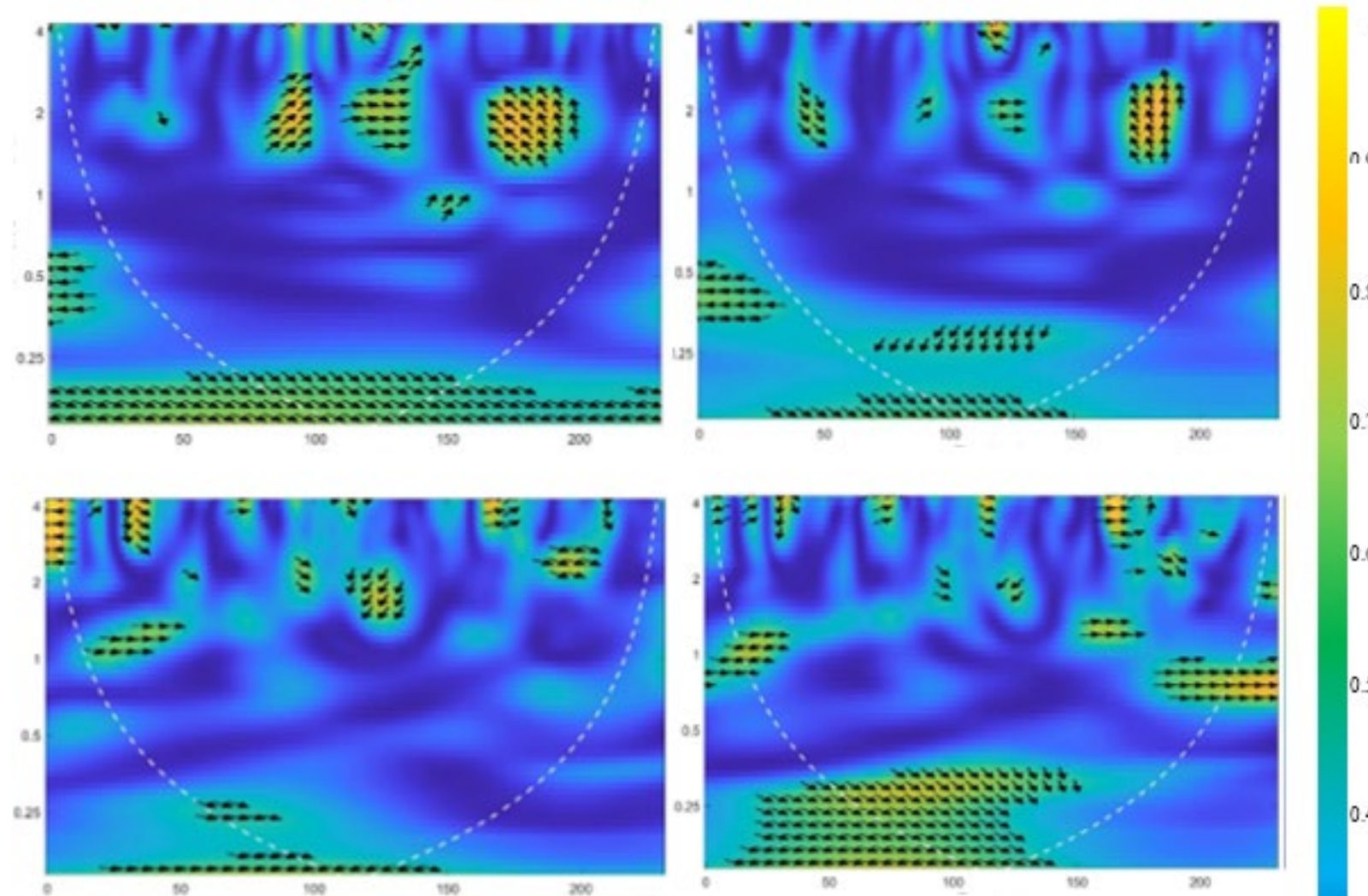

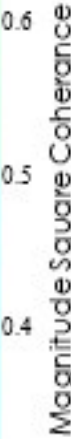
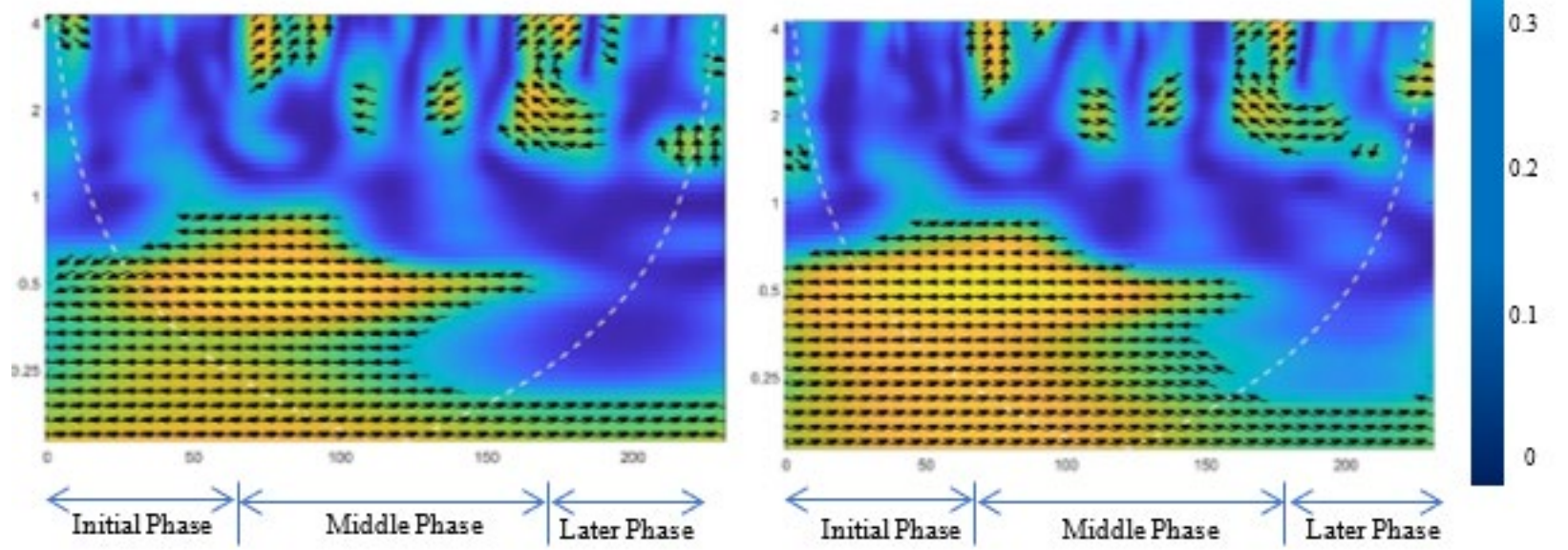

Note: In the above wavelet coherence graphical matrix, wavelet coherence analysis illustration has been presented as: $1 \mathrm{~A}=$ Bitcoin prices and COVID-19 cases, $1 \mathrm{~B}=$ Ethereum prices and COVID-19 cases, $2 \mathrm{~A}=\mathrm{Bitcoin}$ prices and ENS, $2 B=$ Ethereum prices and $E N S, 3 A=$ Bitcoin prices and $V I X$, and $3 C=$ Ethereum prices and $V I X$. The horizontal axis represents 'time (in days)' whereas the vertical axis represents the 'frequency (cycles/sample)'. On the right side of the matrix, the magnitude coherence scale is presented between 0 (blue) and 1 (yellow). The whole sample period is divided into three phases i.e. initial phases from start of the period until 28th February 2020, the middle phase - March 01, 2020 to June 30, 2020, and the later phase ranges from July 1, 2020 to August 18, 2020. 


\section{Conclusion}

The first year of the global coronavirus pandemic has brought on an unprecedented level of economic and financial market uncertainty, due to the scope and speed of its spread and drastic responses to curb the rise of infection numbers. This paper provides some empirical evidence on the information transmission of COVID-19 to cryptocurrencies through economic news and financial market sentiments. VAR Granger Causality/Block Exogeneity Wald Test and Wavelet Coherence Analysis results show that new daily coronavirus cases reported, economic news sentiment and financial market volatility Granger-cause Bitcoin and Ethereum prices. Moreover, the WCA results further reveal that information transmissions flowed significantly during the initial and middle phases of the sample period. Taken together with our findings from impulse responses and variance decomposition, one standard deviation shocks to each explanatory variable can have a persistent effect on cryptocurrencies for up to 2 days and that the VIX Index has a more dominant effect on Bitcoin while ENS impacts Ethereum more significantly. Our study period covers the first 8 months of the unfolding COVID-19 health crisis, which has offered us a unique opportunity to study market reactions to the initial shock of the pandemic. As the global response to this health crisis continues to evolve, further study can be conducted on the transmission of information into cryptocurrencies and other financial assets.

Our findings contribute to the ongoing debate on cryptocurrencies being 'safe havens' in the times of crisis by studying the behaviour of the two top cryptocurrencies during the first year of the spread. Our findings suggest cryptocurrency is a viable asset class at the time of the health crisis and negative economic sentiment. The findings of this study have theoretical implications as they shed some light on the impact of systemic risk and how it transmits into financial assets through channels that measure market sentiment.

\section{References}

Aguilar, P., Ghirelli, C., Pacce, M., \& Urtasun, A. (2020). Can news help measure economic sentiment? An application in COVID-19 times.

Akdağ, S., Kiliç, İ., \& Yildirim, H. (2019). Does VIX scare stocks of tourism companies? Letters in Spatial and Resource Sciences, 12(3), 215-232.

Albulescu, C. (2020). Coronavirus and financial volatility: 40 days of fasting and fear. arXiv preprint arXiv:2003.04005.

Ali, M., Alam, N., \& Rizvi, S. A. R. (2020). Coronavirus (COVID-19)-An epidemic or pandemic for financial markets. Journal of Behavioral and Experimental Finance, 100341.

Benhabib, J., \& Spiegel, M. M. (2019). Sentiments and economic activity: Evidence from US states. The Economic Journal, 129(618), 715-733.

Calomiris, C. W., \& Mamaysky, H. (2019). How news and its context drive risk and returns around the world. Journal of Financial Economics, 133(2), 299-336.

Chen, C., Liu, L., \& Zhao, N. (2020). Fear Sentiment, Uncertainty, and Bitcoin Price Dynamics: The Case of COVID-19. Emerging Markets Finance and Trade, 56(10), 2298-2309.

Choi, S.-Y. (2020). Industry volatility and economic uncertainty due to the COVID-19 pandemic: Evidence from wavelet coherence analysis. Finance Research Letters, 37, 101783. 
Conlon, T., \& McGee, R. (2020). Safe haven or risky hazard? Bitcoin during the Covid-19 bear market. Finance Research Letters, 35, 101607.

Corbet, S., Larkin, C., \& Lucey, B. (2020). The contagion effects of the COVID-19 pandemic: Evidence from gold and cryptocurrencies. Finance Research Letters, 35, 101554.

Crowley, P. M. (2007). A guide to wavelets for economists. Journal of Economic Surveys, 21 (2), 207267.

Da, Z., Engelberg, J., \& Gao, P. (2015). The sum of all FEARS investor sentiment and asset prices. The Review of Financial Studies, 28(1), 1-32.

Demir, E., Bilgin, M. H., Karabulut, G., \& Doker, A. C. (2020). The Relationship between Cryptocurrencies and COVID-19 Pandemic. Available at SSRN 3585147.

Goodell, J. W., \& Goutte, S. (2020). Co-movement of COVID-19 and Bitcoin: Evidence from wavelet coherence analysis. Finance Research Letters, 101625.

Gurdgiev, C., O'Loughlin, D., \& Chlebowski, B. (2019). Behavioral Basis Of Cryptocurrencies Markets: Examining Effects Of Public Sentiment, Fear, And Uncertainty On Price Formation. Journal of Financial Transformation, 49, 110-121.

Iqbal, N., Fareed, Z., Wan, G., \& Shahzad, F. (2020). Asymmetric nexus between COVID-19 outbreak in the world and cryptocurrency market. International Review of Financial Analysis, 73, 101613.

Kang, S. H., Mclver, R. P., \& Hernandez, J. A. (2019). Co-movements between Bitcoin and Gold: A wavelet coherence analysis. Physica A: Statistical Mechanics and its Applications, 536, 120888.

Li, Z., Tian, M., Ouyang, G., \& Wen, F. (2020). Relationship between investor sentiment and earnings news in high-and low-sentiment periods. International Journal of Finance \& Economics.

Mnif, E., Jarboui, A., \& Mouakhar, K. (2020). How the cryptocurrency market has performed during COVID 19? A multifractal analysis. Finance Research Letters, 101647.

Nițoi, M., \& Pochea, M. M. (2020). Time-varying dependence in European equity markets: A contagion and investor sentiment driven analysis. Economic Modelling, 86, 133-147.

Shahzad, S. J. H., Bouri, E., Roubaud, D., Kristoufek, L., \& Lucey, B. (2019). Is Bitcoin a better safe-haven investment than gold and commodities? International Review of Financial Analysis, 63, 322-330.

Shapiro, A. H., Sudhof, M., \& Wilson, D. (2020). Measuring news sentiment.

Smales, L. A. (2017). The importance of fear: investor sentiment and stock market returns. Applied Economics, 49(34), 3395-3421.

Smales, L. A. (2019). Bitcoin as a safe haven: Is it even worth considering? Finance Research Letters, 30, 385-393.

Torrence, C., \& Webster, P. J. (1999). Interdecadal changes in the ENSO-monsoon system. Journal of climate, 12(8), 2679-2690.

Zaremba, A., Szyszka, A., Long, H., \& Zawadka, D. (2020). Business sentiment and the cross-section of global equity returns. Pacific-Basin Finance Journal, 101329. 